\title{
Editorial
}

\section{Social inequalities in cancer incidence and survival: lessons from Danish studies}

Gwenn Menvielle 1 and Anton Kunst 2

1 : Inserm U687, Villejuif, France ; IFR69, Villejuif, France

2 : Dept of Public Health, Erasmus MC, Rotterdam, The Netherlands

The unequal distribution of diseases among population groups has since long attracted the attention of epidemiologists. Large differences in disease risk have repeatedly been observed in relationship to socioeconomic indicators, such as educational level, occupational class and household income (1). With regards to cancer risk, a first comprehensive review of socioeconomic inequalities was published by IARC in 1997 (2). This review covered inequalities in cancer mortality, incidence and survival and discussed many possible explanations. More recently, there have been numerous studies describing social inequalities in cancer mortality (3-7) and survival (8-11), and comparatively slightly fewer studies on social inequalities in cancer incidence (12-15).

This special issue of the European Journal of Cancer makes a unique contribution to the study of social inequalities and cancer. This work involved more than 50 researchers from one single country, Denmark, who all focused on the same objective: investigating social inequalities in cancer incidence and survival in Denmark. Their work was based on a rich data source obtained through the linkage of national registries with high quality information on cancer incidence and survival and on a variety of social indicators and relevant clinical indicators. Such linked datasets are a specific asset of the Nordic countries, and the envy of epidemiologists elsewhere. In the Danish studies, the national cancer registry was linked to medical registers and to social registers such as the population register, the unemployment 
register, and the register for education statistics (16). In all papers included in this special issue (16-27), the authors analysed the linked datasets using the same methods to quantify social inequalities in cancer incidence and cancer survival. The authors used different types of indicators: demographic (e.g. type of district or ethnicity), social (such as education or income) and clinical (including co-morbidities or depression). This systematic work resulted in a comprehensive overview of social inequalities in the incidence and survival of 21 different cancer types, providing much more detail than what is commonly available in international journals.

This overview documented large inequalities in the incidence of many cancer sites, especially lung (17), oesophagus, stomach (18), mouth and pharynx, larynx (19), and cervix (20) (see Table 1). Moderate inequalities were found for pancreas (18), kidney and bladder cancer (21). Inequalities were also indicated for colon and rectum cancer (22). For all these cancer types, higher incidence rates were found among men and women from "lower" social groups. Reverse gradients were shown for malignant melanoma (23), breast cancer (24) and prostate cancer (25), with higher incidence rates among people from "higher" social groups. Inequalities in cancer survival, with higher survival rates among people from higher social groups, were observed for many cancer sites including brain (26), melanoma (23), breast (24), cervical (20), mouth and pharynx, larynx (19), prostate (25), kidney, bladder (21), colon and rectum (22) and non-Hodgkin's lymphoma (27). The magnitude of inequalities however strongly differed between cancer sites. Together, by carefully mapping social inequalities in cancer in Denmark, the Danish studies allowed identifying areas with the largest inequalities that thus require particular attention by professionals and policy makers. 
Can the Danish patterns be assumed to apply to other European countries? The results found for most cancer sites are globally in line with what could be expected from the available literature on incidence and mortality. Thus, the authors supported previous studies in documenting a strong negative association between social position and incidence of lung cancer and cervical cancer, no association for Hodgkin and non-Hodgkin's lymphoma and leukaemia, and a positive association for malignant melanoma, breast cancer and prostate cancer. However, recent overviews have shown wide variations between European countries for some cancer types. This has been found for instance for lung (28) or alcohol related cancers (29). Consequently, for some cancers, the Danish situation may largely differ from that in other countries. For example, socioeconomic inequalities in lung cancer incidence among Danish women (17) were much larger than what is found in other European populations, probably due to the more advanced stage of the smoking epidemic among Danish women than among women in most other European countries (30). Similarly, the Danish studies suggested a higher incidence of cancer of colon and rectum among people from lower social groups (22). This negative association is rarely found in European studies, mostly reporting a positive association (31). This specific finding might reflect particularities of Denmark, such as large socioeconomic inequalities in the prevalence of risk factors including obesogenic diet, physical activity and body mass index. There is evidence to suggest that these inequalities are larger in Denmark than in most other European countries (32).

The comprehensive mapping exercise presented in this special issue cannot be easily replicated in most other European countries, because of the lack of equally comprehensive databases outside Scandinavia. Nonetheless, a number of lessons may be learned and applied to descriptive studies in other parts of Europe. First of all, the Danish work illustrates the great importance of linking cancer registries to population-based registers with information on 
co-morbidities or demographic and socioeconomic characteristics of cancer patients. As an example, such a comprehensive linkage has already been performed for the Turin cancer registry (33). In other situations where an individual linkage is not possible, a start could be made with linking cancer registries to other registries at an ecological level. Studies from different European countries documented large inequalities in cancer survival in relationship to area-based measures of socioeconomic position $(11,34,35)$. In addition, cancer registries should endeavour to routinely record, in addition to tumour characteristics, other information possibly linked to cancer survival. Thus, in the Eindhoven Cancer Registry, severe comorbidities at the time of diagnosis are recorded since $1993(36,37)$.

A large body of the literature deals with social inequalities in cancer mortality. Inequalities in mortality reflect the combined effect of inequalities in incidence and inequalities in casefatality. The contribution of these two components may greatly differ between cancer types. In Denmark, lung cancer showed large incidence but small survival inequalities (17), while the reverse pattern was observed for non-Hodgkin's lymphoma (27). For breast cancer, inequalities favouring women from "low" social groups were found for incidence, whereas inequalities favouring women from "high" social groups were found for survival (24). Also in other European countries, epidemiologists should attempt to look beyond mortality and to identify inequalities in incidence and in survival respectively, in agreement with a suggestion to interpret trends in these disease properties adequately (38).

The Danish studies also underline the importance of statistical power. This is essential to draw conclusions regarding the presence of inequalities but also their magnitude. Sufficient statistical power allows ruling out the possibility that the findings are due to random variation, as in most Danish studies. Thus, the Danish studies demonstrated enormous differences in the 
magnitude of differences between cancer sites: cancer incidence among men with basic education (when compared with men with high-school education) was increased by about $50 \%$ for lung cancer compared to only a $15 \%$ for bladder cancer.

The authors used six socio-economic indicators (level of education, disposable income, affiliation to work market, social class, housing tenure and size of dwelling) as well as four demographic indicators (gender, cohabitation status, type of district and ethnicity) (16). It is important to utilise different socioeconomic indicators as they represent different forms of socioeconomic (dis)advantage and in addition they are formed during different phases of the life course. In addition, the consideration of different complementary indicators helps to identify as accurately as possible the socioeconomic groups where cancer risk is increased most. Increased risk of many cancer types was observed in relationship to low educational level - which is the most widely used socioeconomic indicator in most European countries but also in relationship to other indicators such as employment status and housing tenure. These large inequalities were also observed after adjusting for educational level, suggesting an independent effect of other variables (39). It is remarkable that for many cancer types inequalities were larger when using housing variables than income (39). This suggests that wealth as accumulated over the life course, and as reflected in ownership and quality of housing, may be a useful predictor for increased cancer incidence.

Social class as defined by occupational class is traditionally considered one of the most important indicators to characterize people's socioeconomic position. A previous study suggested that occupational class was more strongly associated with cancer mortality than educational level (40). In most Danish studies, occupational class was associated with the risk of cancer, although to a generally lesser extent than education and income. Nonetheless, also 
when controlling for the effects of income and educational level, an independent effect of occupational class was observed for many cancer types. This effect might perhaps reflect factors such as access to influential social networks, the influence of colleagues on health behaviours, or occupational exposures to carcinogens. Crucial for further analysis and interpretation is the choice of an appropriate classification of occupational classes. In the Danish studies, the classification was based on the theory of the "creative class" (41). This classification is however rarely used in studies on social inequalities in health. We would recommend applying classifications that are based on established traditions in social stratifications research, such as the European Socio-Economic Classification (ESEC) (42).

The Danish studies raise questions about causes underlying the generally higher cancer incidence and lower cancer survival in lower socioeconomic groups. In social epidemiology, a common hypothesis is that a higher exposure to important risk factors like smoking explains the higher incidence of specific cancer types (e.g. lung cancer) in low social group. In this framework, risk factors should be seen as "intermediate factors" or "mediators", and not as confounders, in the association between cancer incidence and socio-economic status, the latter being a "fundamental cause" that determines people's exposure to these risk factors (43). The Danish studies included in the special issue do not address the role of such risk factors, although many do offer explanations when interpreting the results (17-27). Previous studies from other countries yielded evidence on risk factors that explained some of, but not all, of the observed inequalities in cancer incidence. Such studies have aim to explain the inequalities in the incidence of many different cancer sites including the cancer of the lung (44), larynx (45), prostate (46), bladder (47), oesophagus and stomach (48) or breast (49). Regarding cancer survival, studies have consistently observed that the stage at diagnosis only partly explained the poorer survival found among more deprived social groups (50). 
The contribution of co-morbidities to inequalities in cancer survival, has been investigated in a number or studies, with inconsistent results (50). The presence of co-morbidities is associated with a poorer survival for some cancer sites $(36,37)$. The presence of co-morbidity may thus partly explain the poorer survival found among subjects from lower social class (51) but this issue has been little investigated. In the Danish studies, the presence of co-morbidities was associated with poorer cancer survival for many various cancer sites including the prostate (25), the kidney (21), the stomach (18) or the leukaemia (27). It is uncertain, however, to what extent the poorer cancer survival of lower socioeconomic groups in Denmark can be attributed to a higher co-prevalence of other diseases.

Finally, there is the question how socioeconomic inequalities in cancer could be diminished by reducing incidence and improving survival of patients from lower socioeconomic groups. A main strategy is primary prevention aimed to decrease both cancer incidence rates and social inequalities in cancer incidence. For example, to decrease inequalities in lung cancer incidence in Denmark, tobacco control policies should be targeted towards people from the lower social groups, where the consumption is the highest (52). It is important to implement as effective as possible preventive policies. An ongoing European project, the Eurocadet project, will help to identify such preventive strategies (53). This project will provide estimations of the effects of different strategies in reducing social inequalities in cancer incidence in many different European countries, and thus give useful input for public health policies.

In addition, important reductions in inequalities could be achieved by improving access to and use of health care system in all population groups, such as access to reference care centres and 
state-of-art treatments. Moreover, as organised programs of cancer screening are effective in improving survival rates (54), strategies should be developed to promote screening among all social groups, and especially those groups where attendance rates are the lowest. The latter is shown to be possible through pro-active invitation strategies specifically targeting to more vulnerable groups (55). This is especially relevant as it has been shown that the implementation of mass screening could lead to an increase in social inequalities in cancer survival, even with a very high participation rate (around 85\%) (56). In addition, the role of co-morbidities in social inequalities in cancer survival has not been studied extensively and should be further investigated, as co-morbidities may partly account for the worse survival observed among patients from low social groups (51).

While an important challenge for Denmark and other European countries is to improve national rates of cancer survival, an additional challenge will be to reduce social inequalities in cancer survival at the same time. Unfortunately, over the past decades, increase in survival rates tended to concur with an increase in social inequalities in cancer survival $(11,34)$. Health care policies should be specifically developed to ensure more equitable trends in survival in the years to come.

\section{References}

1. Mackenbach JP, Stirbu I, Roskam AJ, et al. Socioeconomic inequalities in health in 22 European countries. N Engl J Med. 2008 Jun 5;358(23):2468-81.

2. Social inequalities and cancer. Lyon: International Agency for Research on Cancer; 1997. 
3. Menvielle G, Kunst AE, Stirbu I, et al. Educational differences in cancer mortality among women and men: a gender pattern that differs across Europe. Br J Cancer. 2008 Mar 11;98(5):1012-9.

4. Albano JD, Ward E, Jemal A, et al. Cancer mortality in the United States by education level and race. J Natl Cancer Inst. 2007 Sep 19;99(18):1384-94.

5. Ezendam NP, Stirbu I, Leinsalu M, et al. Educational inequalities in cancer mortality differ greatly between countries around the Baltic Sea. Eur J Cancer. 2008 Feb;44(3):454-64.

6. Borrell C, Cortes I, Artazcoz L, Molinero E, Moncada S. Social inequalities in mortality in a retrospective cohort of civil servants in Barcelona. Int $\mathrm{J}$ Epidemiol. 2003;32(3):386-9.

7. Menvielle G, Luce D, Geoffroy-Perez B, Chastang JF, Leclerc A, Edisc group. Social inequalities and cancer mortality in France. 1975-1990. Cancer Causes Control. 2005;16(5):501-13.

8. Coleman MP, Babb P, Sloggett A, Quinn M, De Stavola B. Socioeconomic inequalities in cancer survival in England and Wales. Cancer. 2001 Jan 1;91(1 Suppl):208-16.

9. Sloggett A, Young H, Grundy E. The association of cancer survival with four socioeconomic indicators: a longitudinal study of the older population of England and Wales 1981-2000. BMC Cancer. 2007;7:20.

10. Rosso S, Faggiano F, Zanetti R, Costa G. Social class and cancer survival in Turin, Italy. J Epidemiol Community Health. 1997;51(1):30-4.

11. Shack LG, Rachet B, Brewster DH, Coleman MP. Socioeconomic inequalities in cancer survival in Scotland 1986-2000. Br J Cancer. 2007 Oct 8;97(7):999-1004.

12. Hemminki K, Zhang H, Czene K. Socioeconomic factors in cancer in Sweden. Int J Cancer. 2003 Jul 10;105(5):692-700.

13. Conway DI, Brewster DH, McKinney PA, Stark J, McMahon AD, Macpherson LM. Widening socio-economic inequalities in oral cancer incidence in Scotland, 1976-2002. Br J Cancer. 2007 Mar 12;96(5):818-20.

14. Pukkala E, Weiderpass E. Time trends in socio-economic differences in incidence rates of cancers of the breast and female genital organs (Finland, 1971-1995). Int J Cancer. 1999;81(1):56-61.

15. Weiderpass E, Pukkala E. Time trends in socioeconomic differences in incidence rates of cancers of gastro-intestinal tract in Finland. BMC Gastroenterol. 2006;6:41.

16. Dalton S, Steding-Jessen M, M G, Frederiksen K, Engholm G, Schüz J. Social inequality and incidence of and survival from cancer in a population based study in Denmark, 1994-2003: Background, aims, material and methods. Eur J Cancer. 2008; in Press.

17. Dalton S, Steding-Jessen M, Engholm G, Schüz J, Olsen J. Social inequality and incidence of and survival from lung cancer in a population-based study in Denmark, 19942003. Eur J Cancer. 2008; In Press.

18. Baastrup R, Sorensen M, Hansen J, Hansen R, Würtzen H, Winther J. Social inequality and incidence of and survival from cancers of the oesophagus, stomach and pancreas in a population-based study in Denmark, 1994-2003. Eur J Cancer. 2008;In Press.

19. Andersen Z, Lassen C, Clemmensen I. Social inequality and incidence of and survival from cancers of the mouth, pharynx and larynx in a population-based study in Denmark, 1994-2003. . Eur J Cancer. 2008; In Press.

20. Jensen K, Hannibal C, Nielsen A, et al. Social inequality and incidence of and survival from cancer of the female genital organs in a population-based study in Denmark, 1994-2003. Eur J Cancer. 2008; In Press.

21. Eriksen K, Petersen A, Poulsen A, Deltour I, Raaschou-Nielsen O. Social inequality and incidence of and survival from cancers of the kidney and urinary bladder in a populationbased study in Denmark, 1994-2003. Eur J Cancer. 2008;In Press. 
22. Egebjerg R, Halkjaer J, Rottman N, Hansen L, Holten I. Social inequality and incidence of and survival from cancers of the colon and rectum in a population-based study in Denmark, 1994-2003. Eur J Cancer. 2008;in Press.

23. Birch-Johansen F, Hvilsom G, Kjaer T, Storm H. Social inequality and incidence of and survival from malignant melanoma in a population-based study in Denmark, 1994-2003. Eur J Cancer. 2008; In Press.

24. Carlsen K, Hoybye M, Dalton S, Tjonneland A. Social inequality and incidence of and survival from breast cancer in a population-based study in Denmark, 1994-2003. Eur J Cancer. 2008; In Press.

25. Marsaa K, Johnsen NF, Bidstrupp P, Johannesen-Henry C, Friis S. Social inequality and incidence of and survival from male genital cancer in a population-based study in Denmark, 1994-2003. Eur J Cancer. 2008; In Press.

26. Schmidt L, Nielsen H, Schmiedel S, Johansen C. Social inequality and incidence of and survival from tumours of the central nervous system in a population-based study in Denmark, 1994-2003. Eur J Cancer. 2008;In Press.

27. Roswall N, Olsen A, Christensen J, Rugbjerg K, Mellemkjaer L. Social inequality and incidence of and survival from Hodgkin lymphoma, non-Hodgkin lymphoma and leukemia in a population-based study in Denmark, 1994-2003. Eur J Cancer. 2008;In Press.

28. Mackenbach JP, Huisman M, Andersen O, et al. Inequalities in lung cancer mortality by the educational level in 10 European populations. Eur J Cancer. 2004;40(1):126-35.

29. Menvielle G, Kunst AE, Stirbu I, et al. Socioeconomic inequalities in alcohol related cancer mortality among men: to what extent do they differ between Western European populations? Int J Cancer. 2007 Aug 1;121(3):649-55.

30. Jha P, Peto R, Zatonski W, Boreham J, Jarvis MJ, Lopez AD. Social inequalities in male mortality, and in male mortality from smoking: indirect estimation from national death rates in England and Wales, Poland, and North America. Lancet. 2006 Jul 29;368(9533):36770 .

31. Faggiano F, Partanen T, Kogevinas M, Boffetta P. Socioeconomic differences in cancer incidence and mortality. IARC Sci Publ. 1997;138:65-176.

32. Eurothine. Tackling health inequalities in Europe: An integrated approach EUROTHINE. Final report: Dept of Public Health. University Medical Centre Rotterdam. The Netherlands.; 2007.

33. Faggiano F, Zanetti R, Costa G. Cancer risk and social inequalities in Italy. J Epidemiol Community Health. 1994;48(5):447-52.

34. Coleman MP, Rachet B, Woods LM, et al. Trends and socioeconomic inequalities in cancer survival in England and Wales up to 2001. Br J Cancer. 2004 Apr 5;90(7):1367-73.

35. Dejardin O, Remontet L, Bouvier AM, et al. Socioeconomic and geographic determinants of survival of patients with digestive cancer in France. Br J Cancer. 2006 Oct 9;95(7):944-9.

36. Janssen-Heijnen ML, Lemmens VE, van den Borne BE, Biesma B, Oei SB, Coebergh JW. Negligible influence of comorbidity on prognosis of patients with small cell lung cancer: a population-based study in the Netherlands. Crit Rev Oncol Hematol. 2007 May;62(2):172-8. 37. van Spronsen DJ, Janssen-Heijnen ML, Lemmens VE, Peters WG, Coebergh JW. Independent prognostic effect of co-morbidity in lymphoma patients: results of the population-based Eindhoven Cancer Registry. Eur J Cancer. 2005 May;41(7):1051-7.

38. Karim-Kos HE, de Vries E, Soerjomataram I, Lemmens V, Siesling S, Coebergh JW. Recent trends of cancer in Europe: A combined approach of incidence, survival and mortality for 17 cancer sites since the 1990s. Eur J Cancer. 2008 Feb 13. 
39. Dalton S, Schüz J, Johansen $\mathrm{C}$, et al. Social inequality and incidence of and survival from cancer in a population-based study in Denmark, 1994-2003: summary of findings. Eur J Cancer. 2008; In Press.

40. Davey Smith G, Hart C, Hole D, et al. Education and occupational social class: which is the more important indicator of mortality risk? $\mathrm{J}$ Epidemiol Community Health. 1998;52(3):153-60.

41. Florida R. The rise of the creative class. New York: Basic books; 2002.

42. Rose D, Harrison E. The European socio-economic classification: a new social schema for comparative European research. European Societies. 2007 July 2007;9(3):459-90.

43. Bauman AE, Sallis JF, Dzewaltowski DA, Owen N. Toward a better understanding of the influences on physical activity: the role of determinants, correlates, causal variables, mediators, moderators, and confounders. Am J Prev Med. 2002 Aug;23(2 Suppl):5-14.

44. Mao Y, Hu J, Ugnat AM, Semenciw R, Fincham S. Socioeconomic status and lung cancer risk in Canada. Int J Epidemiol. 2001;30(4):809-17.

45. Menvielle G, Luce D, Goldberg $P$, Leclerc A. Smoking, alcohol drinking, occupational exposures and social inequalities in hypopharyngeal and laryngeal cancer. Int $\mathbf{J}$ Epidemiol. 2004;33(4):799-806.

46. Nielsen NR, Kristensen TS, Zhang ZF, Strandberg-Larsen K, Schnohr P, Gronbaek M. Sociodemographic status, stress, and risk of prostate cancer. A prospective cohort study. Ann Epidemiol. 2007 Jul;17(7):498-502.

47. Goy J, Rosenberg MW, King WD. Health risk behaviors: examining social inequalities in bladder and colorectal cancers. Ann Epidemiol. 2008 Feb;18(2):156-62.

48. Nagel G, Linseisen J, Boshuizen HC, et al. Socioeconomic position and the risk of gastric and oesophageal cancer in the European Prospective Investigation into Cancer and Nutrition (EPIC-EURGAST). Int J Epidemiol. 2007 Feb;36(1):66-76.

49. Strand BH, Tverdal A, Claussen B, Zahl PH. Is birth history the key to highly educated women's higher breast cancer mortality? A follow-up study of 500,000 women aged 35-54. Int J Cancer. 2005 Dec 20;117(6):1002-6.

50. Woods LM, Rachet B, Coleman MP. Origins of socio-economic inequalities in cancer survival: a review. Ann Oncol. 2006 Jan;17(1):5-19.

51. Dalton SO, Ross L, During $M$, et al. Influence of socioeconomic factors on survival after breast cancer--a nationwide cohort study of women diagnosed with breast cancer in Denmark 1983-1999. Int J Cancer. 2007 Dec 1;121(11):2524-31.

52. Giskes K, Kunst AE, Ariza C, et al. Applying an equity lens to tobacco-control policies and their uptake in six Western-European countries. J Public Health Policy. 2007 Jul;28(2):261-80.

53. The Eurocadet project. http://www.eurocadet.org/index.php?nav id=267. accessed $06 / 15 / 2008$.

54. Norman SA, Russell Localio A, Weber AL, et al. Protection of mammography screening against death from breast cancer in women aged 40-64 years. Cancer Causes Control. 2007 Nov; 18(9):909-18.

55. Gupta S, Roos LL, Walld R, Traverse D, Dahl M. Delivering equitable care: comparing preventive services in Manitoba. Am J Public Health. 2003;93(12):2086-92.

56. Louwman WJ, van de Poll-Franse LV, Fracheboud J, Roukema JA, Coebergh JW. Impact of a programme of mass mammography screening for breast cancer on socioeconomic variation in survival: a population-based study. Breast Cancer Res Treat. 2007 Nov;105(3):369-75. 
Table 1: Cancer incidence rate ratios and 5 -year relative survival by education among men and women in Denmark.

basic or high school/higher

\begin{tabular}{|c|c|c|c|c|}
\hline Cancer site & Men & Women & Men & Women \\
\hline Mouth and pharynx & $1.43^{\#}$ & 1.25 & $30 / 39$ & $44 / 47$ \\
\hline Larynx & $1.67^{\#}$ & $3.23^{\#}$ & $52 / 59$ & $54 / 65$ \\
\hline Oesophagus & $1.30^{\#}$ & 0.87 & $5 / 7$ & $6 / 16$ \\
\hline Stomach & $1.37^{\#}$ & $1.23^{\#}$ & $13 / 10$ & $16 / 15$ \\
\hline Pancreas & $1.20^{\#}$ & $1.22^{\#}$ & $2 / 3$ & $2 / 2$ \\
\hline Colon & 0.93 & 1.02 & $42 / 46$ & $46 / 49$ \\
\hline Rectum & 1.02 & 1.12 & $44 / 50$ & $51 / 57$ \\
\hline Lung & $1.53^{\#}$ & $1.85^{\#}$ & $7 / 10^{*}$ & $9 / 10$ \\
\hline Breast & & $0.80^{\#}$ & & $77 / 84^{*}$ \\
\hline Cervix & & $1.33^{\#}$ & & $68 / 78^{*}$ \\
\hline Corpus & & 0.98 & & $79 / 81$ \\
\hline Ovary & & 0.97 & & $37 / 36$ \\
\hline Prostate & $0.81^{\#}$ & & $47 / 59 *$ & \\
\hline Testis & 1.00 & & $93 / 97$ & \\
\hline Kidney & $1.22^{\#}$ & $1.54^{\#}$ & $38 / 41$ & $42 / 49$ \\
\hline Bladder & $1.15^{\#}$ & $1.37^{\#}$ & $68 / 75^{*}$ & $62 / 70$ \\
\hline Malignant melanoma & $0.65^{\#}$ & $0.69^{\#}$ & $75 / 81^{*}$ & $86 / 92 *$ \\
\hline Brain and central nervous system & 1.04 & 0.92 & $39 / 47 *$ & $58 / 66^{*}$ \\
\hline Non-Hodgkin's lymphoma & 1.10 & 1.14 & $48 / 58$ & $58 / 65$ \\
\hline Hodgkin's lymphoma & 1.05 & 1.16 & $82 / 76$ & $78 / 90$ \\
\hline Leukaemias & 0.96 & 1.10 & $46 / 54$ & $46 / 52$ \\
\hline All cancers & $1.10^{\#}$ & 1.02 & $37 / 48^{*}$ & $50 / 62 *$ \\
\hline
\end{tabular}


1: Adjusted IRR, incidence rate ratios adjusted for age, period, level of education and disposable income; basic or high-school education compared with higher education. Incidence between 1994 and 2003

2: Cumulative level-specific relative survival in \%. Cancers diagnosed between 1994 and 2003 and followed through 2006

\# $95 \%$ confidence interval excludes 1

* $95 \%$ confidence intervals non-overlapping between levels of indicator 